\title{
I look behind me... genesis of Growing Our Own
}

\begin{tabular}{|c|c|}
\hline Alison Elliott & Brenda Keenan \\
CQUniversity & Catholic Education Office, NT \\
a.elliott@cqu.edu.au & brenda.keenan@cesa.catholic.edu.au \\
\hline
\end{tabular}

Key words: teacher education; Indigenous

\begin{abstract}
This paper offers a critical reflection on the Growing Our Own program, reviewing some of the particularities and challenges facing educators, authorities and communities in the Northern Territory and in so doing elucidates both how and why such a program can sustain the successes that it has achieved.
\end{abstract}

\section{Introduction}

Building a strong Indigenous teacher workforce for remote communities is a key component of improving educational and experiences for Aboriginal and Torres Strait Islander children. Efforts over several decades to build Indigenous teacher capacity for remote communities are well evidenced but there are few Aboriginal (and/or Torres Strait Islander) teachers in remote schools and annual staff churn is the norm. As Hess (1998) contended, this situation is not unexpected given the complexity of remote communities. The challenges of physical isolation are compounded by a shifting policy landscape, frequent administrative changes, and often entrenched bureaucratic resistance to authentic community participation in planning and delivering education. Providing quality teachers for every school has long been a top priority for governments and education authorities but is inherently elusive and challenging in remote, isolated communities.

Issues around teacher quality are amplified by the fact that few teachers in remote communities share the culture (or language) of their students or a sense of 'belonging' to the community. Most teachers in remote schools in the Northern Territory are not local; they come from Darwin or other parts of Australia. Each incoming teacher has to adapt to a new local cultural context as well as to the school. Many teachers are in their first few years of teaching and are still building confidence as teachers and developing their pedagogical repertoire. They must also adjust to Northern Territory policies and curricula, as well as becoming familiar with a new community that is probably vastly different from their home town.

Given on-going research about the positive impact of teacher quality on student learning experiences and outcomes, it makes sense to build teacher quality from within communities where possible, and Growing Our Own was intended to do just that. Teachers who know their communities, families and children have a head start in creating quality learning environments. Growing Our Own was designed to build Indigenous teacher capacity in Catholic Schools located in remote Northern Territory communities. As educators, we recognised the critical role of teachers in improving student performance and, as research at the time was highlighting (Darling-Hammond, 1997, 2003; Hattie, 2003; Rowe, 2003; Ingvarson \& Rowe, 2007), teacher quality is a key pillar of quality student experiences and outcomes.

Ideally, schools in any community should be staffed by teachers who have strong social and cultural ties to their communities and who want to live and work there. Teachers must be able to identify with children and children's families and communicate with families in their home language for real home- school collaboration to occur. However, for a range of complex historical, cultural, social and economic reasons, this sort of connectedness rarely happens in very remote communities. There are very few qualified Aboriginal or Torres Strait Islander teachers who live and work in their remote hometowns. Clearly, many Indigenous people living in remote Australia would make excellent teachers (or doctors, lawyers or 
architects) but they are not in the position to participate in mainstream higher education including teacher education programs. Similarly, there are barriers to participating in traditional distance education and on-line learning programs, including a combination of resource, social and communication challenges.

Catholic Education in the Northern Territory has a long history of working in partnership with local communities and Growing Our Own was intended as another strategy to support connectedness of community and school. Most importantly, the Growing Our Own collaboration was determined to support local educators to become teachers-the best teachers for their communities-a situation that had proved elusive for some time. As an Indigenous school principal said at the time: "I'm the only Indigenous principal (in the Catholic system). I look back and there's no one behind".

\section{The importance of partnerships}

The Charles Darwin University first started to talk about practical options to enhance Indigenous teacher capacity in mid-2007. After a period of brainstorming options, consultation with remote community educators and leaders and our respective colleagues, plus drawing on diverse experiences and research, we proposed what appeared to be a practical approach to leveraging the respective skill sets of our organisations to build teacher Indigenous capacity in collaboration with communities.

Years of literacy and numeracy benchmarking at local and national levels had shown that achievement of remote Indigenous students was generally significantly poorer than that of other students. It was well documented that a complex matrix of factors including inherent disadvantages associated with isolation, policy and funding cycles, and the challenges around attracting and keeping the best and brightest teachers, mitigated against student success. As any educator or community leader will attest, continuously shifting policy landscapes, endless 'new' curriculum and teaching initiatives, pilot projects, program trials, and recycled 'initiatives' are rarely successful.

With the knowledge of research about teacher quality and effectiveness front-of-mind (e.g. DarlingHammond, 1999; Hattie, 2003; Rowe, 2003), our aim was to develop a sustainable strategy to build Indigenous teacher capacity for remote schools. It was important that this strategy avoid any focus on supposed 'problems' with schools, students or communities. Rather, we were seeking a true partnership that would support communities to 'grow their own' teachers starting from a strengths-based model (Gonzalez, Moll, \& Amanti, 2005) that is, with communities' own highly regarded resource, existing Teacher Assistants.

A key message from our previous work, and that of various educational leaders, was that a successful educational enterprise must be a partnership between community and school, whatever the context (Epstein, 2001; Sarra, 2003; Mellor \& Corrigan, 2004; Elliott, 2006). Successful educational outcomes for students are rarely achieved in stand-alone, one off projects. Equally though, while the concept of 'partnership' is relatively easy to acknowledge in principle, the process of forging functional and sustainable partnerships is much more challenging. Sustainable partnerships have to be 'led and nurtured' (National Curriculum Services, 2013).

Central to our thinking about this partnership was the need for it to be 'place-based' and in this context, 'place' referred to each of the remote communities in which there was a Catholic school. Clearly, a community in the far northern tip of Australia is considerably different to one in the Central Desert region. Each has its own identity, language, traditions, cultures and connections with country. Significantly, we recognised that the 'starting point' for any initiative must be the cultural and educational strengths and capacities within communities. Given our roles in the Northern Territory education sector at the time, the local and national appetite to improve educational opportunities in remote communities, and appreciation of the talented Aboriginal Teaching Assistants and educational support teams already working in schools, we felt confident to move forward with a proposal to support building Indigenous teacher capacity Growing Our Own. 


\section{The Northern Territory landscape}

The Northern Territory is sparsely populated region with some 212,000 people (in 2011) spread over a huge area of about $1,420,970$ square kilometres. It has a number of remote and very remote communities with a predominantly Aboriginal population. These communities have generally been characterised by rich cultural traditions and connectedness to country, often enveloped in poverty. They tend to have limited access to services and development opportunities including health and education. Challenges faced by schools in remote and very remote communities are largely around resourcing and access issues. This is due to remoteness and isolation including attracting and retaining qualified teachers, variable internet access, supporting large numbers of learners for whom English is a second or third language, and poor school attendance. Challenges are exacerbated by roads that can be cut off by flood water for months on end, expensive housing, lack of services and fresh food, and limited employment and transport options. Most professionals, such as health workers and teachers, come from outside the communities. Many professionals work on a Fly-In-Fly-Out (FIFO) basis, including curriculum and specialist education support personnel.

Catholic Education has a long history of service provision in remote Northern Territory communities and manages one-school per community in five key locations.

- Ltyente Apurte Community Education Centre (Santa Teresa)

- Murrupurtiyanwu Catholic School (Bathurst Island)

- St Francis Xavier Catholic School (Daly River)

- Our Lady of the Sacred Heart Thamarrurr Catholic School (Wadeye)

- Xavier Community Education Centre (Bathurst Island).

These schools were the main sites for Growing Our Own. Participation opportunities were afforded to Indigenous staff who were working in these Catholic provincial schools.

Teaching Indigenous students is a core role of Catholic Education in the Northern Territory. With growing Indigenous enrolments in the all schools, an ongoing challenge for Catholic Education, indeed all educational sectors in the Northern Territory, has been to attract, develop and retain skilled, experienced teachers and educational leaders. This challenge has been particularly significant in remote communities. High rates of teacher and staff turnover make it difficult for schools to deliver quality teaching that comes through teacher experience and understanding of the local environment and continuity of program delivery.

Catholic Education's long involvement in schooling demonstrated that local Indigenous educators were more likely to stay working at their local school than were non-resident contract teachers. In addition, teachers and other educators from within local communities provided a clearer link between the school and the community. Experience showed that local Indigenous teachers were also best placed to deliver and plan the curriculum around Indigenous languages and culture. By the early 2000s though, many trained Indigenous teachers were being lost from the system with a large cohort of women expected to retire by the end of the decade. Few Indigenous people appeared to be entering teacher training and the number applying for teaching positions in Catholic Education was negligible. 
Image 1: Catholic Education remote community schools (highlighted)

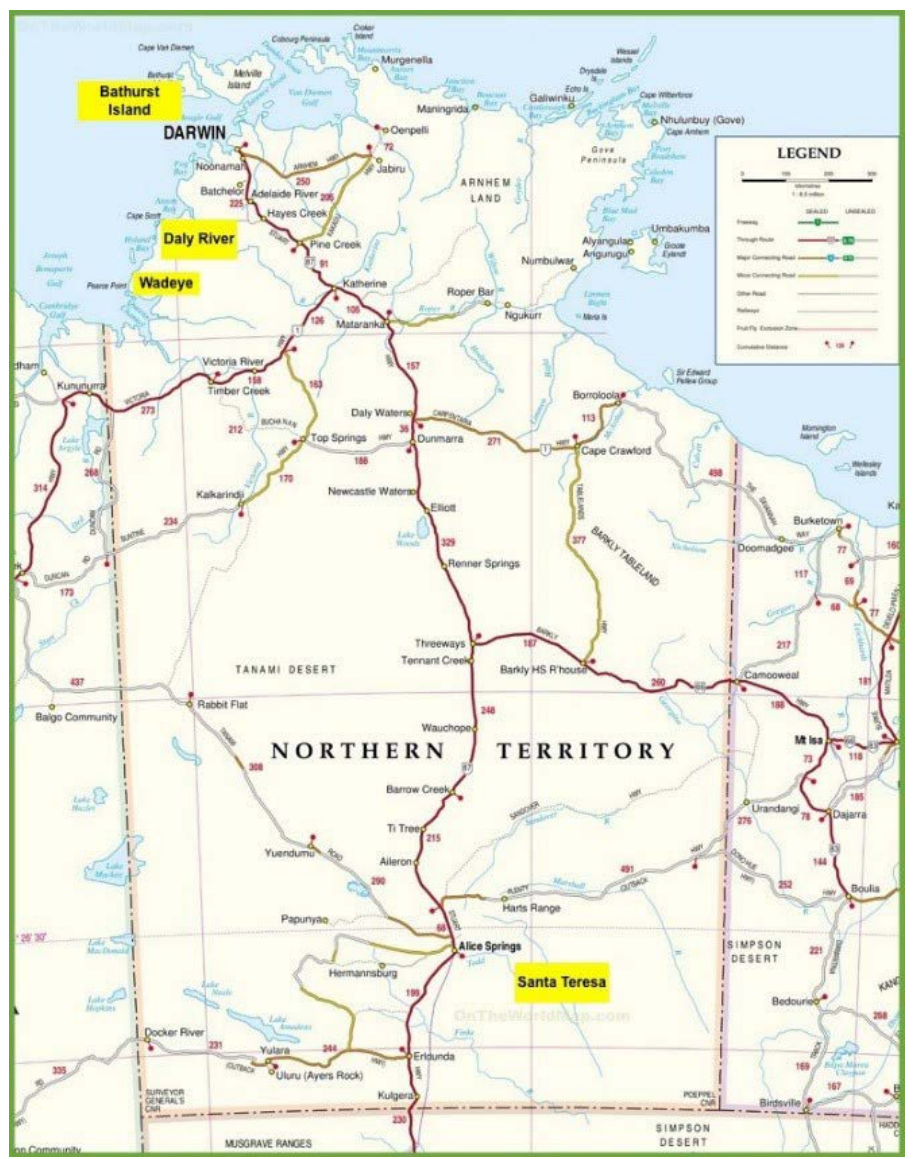

Source: http://www.ontheworldmap.com

\section{Program foundations}

In thinking about building Indigenous teacher capacity and improving educational outcomes for students, our professional experiences indicated that any capacity building initiative had to be strategic, long term and in partnership with communities. As a system of schools, Catholic Education is very specific and clearly aspirational in its call for:

- Covenant relationships.

- Being consciously transformational.

- Commitment to personal, professional and communal growth.

- Dedication to students and learning.

Across the system, Catholic Education employed relatively large numbers of Aboriginal Teaching Assistants and of this group, many had excellent potential to become teachers. There was a further untapped pool of Indigenous staff working in schools as Indigenous Education Workers who were also interested in teaching, but who found current teacher training courses inaccessible, often irrelevant and inconceivable for a range of reasons. As was indicated at the time and quoted in the original funding submission:

Focus on the capacities and potential of Indigenous students is required to avoid them being inappropriately channeled into the most convenient or lowest entry options, such as Community Development Employment Projects (CDEP) or preparatory VET courses. Many 
Indigenous students would benefit from higher-level VET courses or tertiary education but do not feel capable enough or the possibility has not entered their horizons. There is a role for universities to collaborate more closely with schools and TAFE colleges to raise Indigenous students' confidence and perceptions of the relevance and attainability of higher education. (Ministerial Council on Education, Employment, Training and Youth Affairs, 2006)

We stressed that our 'approach to Indigenous teacher training and recruitment needed to change'. We highlighted the need to be 'strategically bold, to approach and develop Indigenous teacher training creatively, differently and with purpose - a new way of doing, a new way of being.' In arguing a funding rationale to develop Growing Our Own, we highlighted that Catholic Education Northern Territory was seeking:

- Indigenous teachers and staff from within each Indigenous Catholic Community School.

- To promote the teaching profession as a positive and attainable pathway and support Indigenous graduate students with corridors leading to the teaching profession.

- A long-term career framework for Indigenous staff across our system of schools.

- A 'two-way' process of 'academic recognition-for Indigenous teacher education students to be supported by experienced mentors, and for mentors to be supported by Indigenous educatorswith both pathways academically recognised and both ways appropriately resourced and managed-a notion of 'authentic counterparts'.

- Teachers who understand the contextual environment of Indigenous students and who value their cultural traditions.

- The best teachers for Indigenous students.

- Teachers with good technical skills who are exemplary practitioners.

- Teachers who could build and sustain strong school, community and student relationships.

- To identify positive entry and exit points in teacher education courses to meet the individual aspirations and skills of Indigenous students.

- To develop better and different transitional arrangements from VET certificate courses and allied educational work roles, including better use of Recognition of Prior Learning to articulate into a degree level qualification.

- To implement processes of place-based training, on-site recognition and on-site teaching placements.

- Provide a coordinated and strategic approach to teacher education for remote Indigenous students, appropriately resourced and managed.

- To work with the Northern Territory Teacher Registration Board to clearly identify appropriate standards, skills and qualities essential for teachers working with Indigenous students.

In summary, we envisaged Growing Our Own as a long term, sustainable approach that would provide creative and accessible pathways to teaching. Central to its conception were commitment to pedagogies that would draw and build on the cultural skills and expertise of Indigenous participants. These approaches would simultaneously enrich the understandings of mentor and classroom teachers' and lecturing (facilitating) staff about local Indigenous ways of knowing, being, learning and doing. This multipronged approach recognised that academic staff must work in culturally effective and educationally authentic and significant ways with Indigenous learners. 


\section{Planning, structure and delivery}

Growing Our Own developed as a partnership between Charles Darwin University (CDU) and Catholic Education Northern Territory over 2008-09 and was initially funded by a $\$ 1.82$ million Commonwealth government grant. The program was designed to support Aboriginal Teaching Assistants who worked in one of five remote Catholic Primary schools to complete CDU's Bachelor of Teaching and Learning degree in a way that was personalised to the needs of individuals and communities. The course was to be delivered 'in-place' over teaching periods aligned with the 4-term school year. This time frame was more consistent with the rhythm of school, family and community life than traditional University teaching semesters. It was anticipated that students would complete the course over a two to three-year period, depending on each student's personalised pathway and individual factors such as academic credit received for previous study and work experience.

As mentioned earlier, the principles underpinning the delivery design and framework focused on valuing and actively embracing cultural knowledges to build culturally authentic ways of knowing and doing 'schooling'. These were designed to meet CDU's Bachelor of Teaching and Learning course learning outcomes and Northern Territory Teacher Registration Board graduate standards. The program used oneto-one and small group tutoring for each unit or cluster of units within each community. These sessions were complemented by support from site-based mentor teachers and on- line resources and activities to personalise learning and provide access to the wider world of education, teaching and learning. Each remote school established a dedicated teaching space in which students could work and study and all students were provided with a computer.

Customisation of the Bachelor of Teaching and Learning course was designed to build on students' existing teaching, community and cultural skills. Students were selected to participate in Growing Our Own on the basis of a combination of personal interest and commitment, community and school recommendation, and family commitment. Each student's participation was endorsed by his or her community and family as well as the school. Simultaneously, course design and teaching approaches were developed in collaboration with leading Indigenous educators across each community, Catholic Education and CDU staff. Special consideration was given to participants' relationships within their communities, kinship and group alignments, and family or other cultural and community responsibilities and obligations.

Students in the first cohort were employed as Aboriginal Teaching Assistants in their community's school. Most had worked there for many years and were considered the 'backbone' of the school and their community, sometimes with a history of teaching children from multiple generations. They were embedded in their communities. Mostly, they were the mothers, daughters, sisters, cousins and aunties of many children in the school and community and they brought a wealth of knowledge, competence and skill to their schools and communities. In planning our delivery approach, we wanted to honour, celebrate and leverage this community connectedness as the basis for learning to be a teacher in terms of contemporary curriculum and pedagogy and, ultimately, Northern Territory Teacher Registration.

In addition, most Aboriginal Teaching Assistants had completed components of various Vocational Education and Training (VET) qualifications such as the Certificate III in Children's Services (now the Certificate III in Early Childhood Education and Care). Because of these prior learning and professional experiences an RPL (Recognition of Prior Learning) assessment was negotiated for each student. Generally, this RPL meant that students were required to complete about two thirds to three quarters of the degree rather than the entire degree.

Simultaneously, the Growing Our Own framework was designed to support CDU academic staff and Aboriginal Teaching Assistants' classroom teachers to enrich their understandings of local Indigenous cultures and ways of knowing, being and doing. As Darling-Hammond (1999) indicated, an important part of building teacher quality is for teachers to work together to scaffold each other's learning and to share pedagogical journeys. Underpinning this working 'side-by-side' idea was the importance of learning about each other's cultural and pedagogical perspectives and infusing cultural identities and knowledges across all aspects of the program to strengthen learning for all participants. This culturally responsive and engaging orientation stressed Indigenous educators' strong sense of cultural identity and focus on learning styles that valued collaborative work. Equally, it recognised the importance of mainstream educational values such as that every Australian child must be a fluent speaker, reader and 
writer in English. Concomitantly, the Growing Our Own framework embraced the University's mission to work in more culturally effective and educationally significant ways with Indigenous learners. Fortunately, digital technologies enabled access to a range of resources available to on-campus students or online students in any other part of the country. Scaffolding personalised learning in this way meant that mentor/ classroom teachers, Aboriginal Teaching Assistants enrolled in the Degree, and CDU staff were able to calibrate personal and local knowledges with mainstream curriculum knowledge and pedagogies, including assessment tasks.

Bachelor of Teaching and Learning units were 'clustered' to fit within the school term model and CDU scheduling patterns. Unit content was customised to align with each student's in-class teaching and learning roles and responsibilities, and was professionally and well as theoretically oriented. Each student was mentored by his or her classroom teacher and the CDU academic assigned to the community/ school. CDU unit coordinators worked with CDU place-based mentors and mentor (classroom) teachers to support students' learning within each community. Delivery was supported by weekly or fortnightly visits from CDU staff complemented by some attendance at on-campus workshops, plus the usual online support afforded to all teacher education students.

A key component of the program was the on-site mentoring. It was intended that Indigenous educators would be mentored by a designated on-site, classroom teacher who in turn was mentored by the Indigenous educator and by a designated CDU staff member. It was also intended that the classroom teacher would enrol in the Master of Education (or Graduate Certificate in Education) and complete the professional learning units within this program. These units could be customised to the context of each teacher.

Conversations with key educational leaders and community elders, together with knowledge from previous work, had highlighted the importance of mentoring and strong, personalised academic support to ensure that Indigenous educators successfully completed their higher education program. Typically, students had many competing work, family and related demands on their energy, time and resources, therefore, one-to-one, sensitive and responsive mentoring was central to timely completion of each unit and of the entire course. It was also acknowledged that some students would need additional support with academic writing.

CDU academic liaison staff worked with the Indigenous educators on a one-to-one or small group basis, depending on the community. The sessions were held on-site in their school for 4 to 6 hours per week (or equivalent), which amounted to 2 to 3 hours per 10 Credit Point unit/subject or the equivalent of faceto-face delivery time for on-campus students. In addition, Indigenous educators had one-to-one tutoring support from their mentor teachers and/or other designated professionals to assist with related learning tasks including completion of assignments. Overall course delivery, administration, logistics and liaison with schools and community personnel was supported by a Project Officer. Given the customised nature of the course, student diversity and remoteness, administration and logistic requirements would be fairly complex.

In addition to day-to-day mentoring support in their normal classroom workplace, it was intended that students would have one day per week for on-site supervised academic work. Most teaching and learning for each unit, including reading, research, and assignment preparation would occur during this time. Generally, as previously mentioned, most teaching and learning tasks were customised and contextualised to ensure close integration between theory and students' classroom practice.

As is the case in any initial teacher education program, central to Growing Our Own and the Bachelor of Teaching and Learning was participation in formal, supervised professional experience in schools. Generally, this was completed in students' own communities and workplaces, but also, where possible in schools outside their own community. It was also planned that students would participate in a CDU oncampus workshop (in Darwin or Alice Springs) for 3 days twice per year for intensive work in their units and most importantly when they commenced the course. These workshops covered orientation to teaching, library research, familiarisation with schools and teaching approaches outside their communities, and contemporary issues in teaching and learning. Similarly, Teacher Mentors would be required to participate in similar on-campus workshops, most importantly when they commenced their mentoring role. 
The initial Growing Our Own proposal envisaged a staged model for building the Indigenous teacher workforce in Catholic schools. First, to build on the existing skills and expertise held by Indigenous educators (mainly Aboriginal Teaching Assistants) in remote Catholic schools. Simultaneously, it supported classroom teachers to become mentors with whom the Aboriginal Teaching Assistants worked to enrich their understandings of Indigenous students' cultural and learning contexts. It was envisaged that later, the project would be able to support young Indigenous people transitioning from school to higher education, hopefully with a focus on initial teacher qualifications.

In developing the Growing Our Own initiative we were mindful of principles that embraced genuine partnerships with community, educational leaders and Aboriginal elders to build local teacher capacity including:

- Design, planning and implementation that was culturally authentic and pedagogically strong.

- Contextual sensitivity and cultural responsiveness in pedagogical design.

- Building knowledge collaboratively including transferability of understandings and skills within and across contexts.

- Integration of traditional teacher education course content and assessment in practical classroom settings.

- Authentic, culturally appropriate ways of progressively documenting student learning outcomes to meet University course and teacher registration requirements.

- Joining culturally and personally relevant Indigenous ways of being, knowing and doing with contemporary curriculum and pedagogical knowledge and teacher professionalism to strengthen pillars and opportunities for children's learning.

- Promoting children's learning and spiritual well-being in authentic ways.

- Supporting the development of home languages (where relevant) while nurturing the parallel development of Standard Australian English.

- Developing 'school ways' of knowing and doing that better connect with family and community and create learning environments and opportunities that engage and enthuse children leading to sustained and deep learning.

Intuitively, we knew that building a strong, grounded Indigenous teaching workforce in remote communities would provide children with better opportunities within mainstream education. As research has indicated, closer school-community connectedness (Epstein, 2001) and consistently effective teaching (DarlingHammond, 1999; Hattie, 2003) would facilitate children's development of skills, knowledge and understandings needed for successful academic outcomes in schooling, improved school retention and lead to employment and /or further educational opportunities. As we said in the original funding submission:

....the key message to be gained from educational effectiveness research is that quality teachers and their professional learning do make a difference in the classroom. It is not so much what students bring with them that really matters, but what they experience on a dayto-day basis in interaction with teachers and other students in classrooms that does.

\section{Risks}

Despite the careful planning and high expectations of Growing Our Own, we highlighted two main risks with the potential for negative impacts on longer term success and sustainability of the program. The first risk was at the student level, the second at a policy level. As our original submission stated: 
Indigenous students in remote communities have complex lives that are adversely affected by a range of poverty-related issues such as ill health, early and unexpected deaths and poor housing. With the best will in the world, and the most flexible and accommodating teacher education program, these can impact negatively on their participation and academic progress. A second concern is the short timeframe and 'pilot' nature of this and other 'intervention' oriented and funded programs. Educational changes and gains happen over time and long-term vision is needed to build social and economic capacity in communities.

Programs such as Growing Our Own must be part of longer-term planning and funding to make sustainable improvements to teacher capacity and to improve learning outcomes in remote communities. Fragmented and unconnected initiatives have little sustained impact on educational and employment capacities of communities. In-community higher education programs need to be part of broader educational policy, strategic directions and in-community action to effectively engage children and families in meaningful and equitable schooling. One-off crisis-initiated responses may well solve some immediate problems but are unlikely to have long term benefits. Educational pathways must engage and empower learners from early childhood through to the work place and higher education. In the longer term, a strong, culturally embedded Indigenous teaching workforce that is committed and accountable to its community, will be well positioned to overcome the intransigence of remote schools. Remote Indigenous children must be scaffolded to develop the skills, knowledge and understandings to fuse cultural knowledges and school-based learnings that promote successful academic outcomes and contemporary employment.

\section{Conclusion}

This paper has highlighted the genesis of Growing Our Own. Remote and very remote communities are dynamic and diverse with strong local and cultural traditions and languages but with a history of challenges around students' engagement with schooling and learning outcomes. All families want the best for their children, but too often school and community views of learning, teaching and educational engagement were disconnected. Traditionally, remote schools have been staffed by teachers from outside communities who may have little affinity with local cultural traditions, no relevant community languages and no plans to work in the community long-term. We also knew that it was difficult, if not impossible, for many local people to pursue higher education or other tertiary programs in distant cities. Factors including cost of education, family and work responsibilities and other local issues prevented people moving from community to access education; similar factors hindered participation in local educational opportunities.

In designing Growing Our Own, we hoped to build Indigenous teaching capacity by harnessing the strengths of in-community Aboriginal Teaching Assistants already employed in schools and over time, build a stronger, educational culture led by local educational leaders and classroom teachers. It has long been acknowledged and celebrated that Aboriginal Teaching Assistants in remote communities are the 'backbone' of their school, the holders of their community's cultural knowledges and languages, and the key conduit to local families. Many have long tenure in local schools but there is little opportunity to move beyond the Aboriginal Teaching Assistant's role.

Remote and very remote communities want to source local teachers embedded in community culture who want to continue living and working in their communities, therefore teacher education would have to be more accessible. Extensive consultation with community leaders, educators and families, confirmed that communities were keen to grow local teacher capacity and valued what we termed 'place-based' education. Communities wanted longer term school leadership to be in local hands to enhance the quality of learning experiences for children and to ensure that local cultural ways and languages were promoted and maintained.

Indigenous disadvantage in higher education is well documented and deeply rooted. Evidence from higher education sources indicates that Indigenous students who enrol in university level studies are more likely than other students to face challenges that impede successful course completion. To ensure 
that each participant in Growing Our Own had the best chance of success, we knew it was important for students to be supported by their communities, that the teaching program was customised to meet specific learning needs, and that each student was supported by strong, personalised mentoring.

Underpinning the course design, structure and provision of resources was a deep understanding of potential course participants' contexts, particularly the often complex and competing personal and professional demands and responsibilities. The design framework encompassed dedicated teaching and study spaces, laptop computers, internet and other learning materials, in-community personalised teaching and mentoring support, and authentic assessment activities to facilitate participants' engagement with learning.

Fundamentally, the Growing Our Own program and curriculum was the same as that for mainstream students studying CDU's accredited 4-year initial teacher education degree program. However, the dedicated funding we sourced plus co-contributions from Catholic Education NT and CDU, enabled teaching approaches that were place-based and personalised and aligned with each student's Aboriginal Teaching Assistant role.

Design and development of Growing Our Own learning and teaching activities was based on the underlying premise that pedagogy must acknowledge each student's unique social, cultural, linguistic and cognitive characteristics and the ways they impact motivation and learning, together with the specific content requirements of the initial teaching qualification. Broadly, it was intended that Indigenous ways of knowing, doing and being and specifically, notions around family-community connectedness, sense of personal and cultural identity, and multi lingual skills would be fore-grounded across all course components. Workshops, tutorials and on-line learning materials were designed to both reflect and extend cultural traditions and simultaneously align with contemporary education theory and practice and relevant curricula and teaching standards. The notions of strong partnerships with community and educational leaders and scaffolding students' learning within the context of their community and existing classroom roles was central to the pedagogical approaches implemented in program design and delivery across each site.

While course design for delivery across local sites had essentially the same structure, purpose and focus on educational expectations and program quality as evidenced in on-campus and traditional external delivery of the Bachelor of Teaching and Learning there were a number of enabling design characteristics, which included:

- Celebrating diverse ways of understanding, knowing and doing in locally relevant and authentic ways consistent with each Assistant Teacher's classroom and community role.

- Engaging with family, community and elders, and the wider school community and/or linked-in services (such as church, health services, playgroups) in course design and on-going nurturing and sustaining students' participation and retention in the program.

- Infusing local cultural identities and knowledge with Northern Territory and national professional teaching expectations and standards.

- Acknowledging and accommodating family, kinship and skin group conventions.

- Recognising the confluences of knowledge, country and place that value and build on domain specific knowledge about community, culture, and learning.

- Appreciating the interrelationships and interactions between multiple factors that facilitate participants' involvement in family and community life and impact on academic and study commitments.

- Responding sensitively to participants' specific learning styles and attention to learners' cognitive, metacognitive (e.g. planning, monitoring, controlling) and affective dimensions of learning (e.g. attitudes to learning, motivation, resilience)

- Recognising that modelling, demonstration and cooperation, collaboration and team work are central to learning and teaching. 
- Highlighting the interconnectedness of learning across domains and the importance of incremental learning progress over time.

- Providing enhanced, customised and personalised academic and professional support.

- Designing pedagogies infused with the day-to-day work of Aboriginal Teaching Assistants.

(Elliott \& Keenan, 2009) 


\section{References}

Darling-Hammond, L. (1997). The Right to learn: A Blueprint for making schools that work. San Francisco, CA: Jossey-Bass.

Darling-Hammond, L. (1999). Doing what matters most: Investing in quality teaching. Kutztown, PA: National Commission on Teaching \& America's Future.

Darling-Hammond, L. (2003). Keeping Good Teachers: Why it Matters and What Leaders Can Do. Educational Leadership, Vol. 60, No. 8 (May 2003), pp. 6-13.

Elliott, A. (2006). Early Childhood Education: Pathways to quality and equity for all children. Australian Council for Educational Research (ACER), Melbourne: ACER. ISBN 9780864317179 (pbk)

Elliott, A., \& Keenan, B. (2009). Growing our own. Paper presented at the ISFIRE (International Symposium for Innovation in Rural Education) Conference, University of New England, Armidale, NSW.

Epstein, J. (2001). School, Family, and Community Partnerships: Preparing Educators and Improving Schools. Boulder, CO: Westview Press.

Gonzalez, N., Moll, L., \& Amanti, C. (2005). Funds of knowledge; Theorizing practices in households, communities and classrooms. Mahwah, NJ: Erlbaum.

Hattie, J. (2003). Teachers make a difference. What is the research evidence? Paper presented at the Australian Council for Educational Research Conference, Melbourne, October 2003. https:// research.acer.edu.au/research_conference_2003/4

Hess, F.M. (1998). Spinning wheels: The politics of urban school reform. Washington, DC: Brooking Institution Press.

Ingvarson, L., \& Rowe, K. (2007). Conceptualising and evaluating teacher quality: Substantive and methodological issues. https://research.acer.edu.au/learning_processes/8

Mellor, S., \& Corrigan, M. (2004). The case for change. A review of contemporary research on Indigenous education outcomes. Australian Education Review, 47, whole issue.

Ministerial Council on Education, Employment, Training and Youth Affairs. (2006). Australian Directions in Indigenous Education 2005 to 2008. Canberra: MCEETYA www.curriculum.edu.au/verve/_ resources/Australian_Directions_in_Indigenous_Education_2005-2008.pdf

National Curriculum Services. (2013). What works. The work program. Sustainable school and community partnerships - a research study. Abbotsford, VIC: National Curriculum Services.

Rowe, K. (2003). The importance of teacher quality as a key determinant of students' experience and outcomes. In M. Meiers (Ed). Proceedings of the Building Teacher Quality Research Conference, pp.15-23. Melbourne: ACER.

Sarra, C. (2003). Young black and deadly: Strategies for improving outcomes for Indigenous students. Quality Teaching Series. Canberra: Australian College of Educators. 